\title{
Vitamin D3: Emerging Role in Murine Toxoplasmosis
}

Enas S. El-Bahaie, Asmaa M. Yousef, Marwa Omar

Department of Medical Parasitology, Faculty of Medicine, Zagazig University,

Zagazig, Egypt..

Corresponding Author

Enas S. El-Bahaie

Mobile:

$+(20) 1275326558$

E mail:

enas.elbahaie@gmail.c om

Key words:

Toxoplasmosis, Mice, Vitamin D3, Nitazoxanide .
Background and aim of the study: Toxoplasmosis is one of the neglected infections which has a global distribution. Effective treatment against toxoplasmosis is hard to accomplish. Accordingly, we tried to investigate the effect of using vitamin $\mathrm{D}_{3}$ alone and in combination with nitazoxanide in Toxoplasma gondii infected mice.

Materials and Methods: The study was conducted on 100 Swiss albino mice which were infected with the avirulent (ME49) Toxoplasma gondii strain. Mice were equally divided into 5 groups: (GI): Infected untreated control group; (GII): Infected and treated by spiramycin; (GIII): Infected and treated by vitamin $\mathrm{D}_{3}$; (GIV): Infected and treated by nitazoxanide and (GV): Infected and received a (vitamin $\mathrm{D}_{3}$-nitazoxanide) combination. The therapeutic impacts of drugs were assessed using; parasitological, histopathological and immunological approaches.
Results: The study showed that the vitamin $\mathrm{D}_{3^{-}}$nitazoxanide combination induced a significant reduction in the parasitic load in the brain sections of the infected mice. We have also reported a delicate balance in the overall immune response against the parasite after using the drug combination. It was noted that vitamin $D_{3}$, used alone, did not significantly reduce the parasitic load despite the notable improvement in the degree of inflammatory infiltration.

Conclusion: The present study revealed that the vitamin $\mathrm{D}_{3}$-nitazoxanide combination was highly potent in restricting the parasitic load. It controlled the infection without the harmful immunopathological impacts. Thus, vitamin $D_{3}$ could be a valuable candidate, either as a sole agent or as an adjunct to other anti-parasitic therapies, in areas where toxoplasmosis is endemic.

\section{INTRODUCTION}

Toxoplasma gondii (T.gondii) is an intracellular apicomplexan parasite with a broad diversity of intermediate hosts, including humans [1]. The parasite affects approximately 30 to $50 \%$ of the world population [2]. Although toxoplasmosis is generally asymptomatic in immunocompetent individuals, it causes severe sequelae in immunocompromised hosts. Active infection during pregnancy may cause abortion, congenital anomalies or perinatal death [3].

Till now, there is no available single gold standard treatment for toxoplasmosis. Pyrimethamine, sulfonamides or their combinations have been frequently used in the severe form of the disease. However, they were commonly associated with numerous undesirable side effects [4].
Spiramycin is a potent bacteriostatic macrolide that has been used in the treatment of different parasitic infections, like; toxoplasmosis and cryptosporidiosis $[\mathbf{5 , 6 ]}$. It produces a high tissue concentration in the placenta without crossing the placental barrier. Accordingly, it is the drug of choice against T.gondii infection during pregnancy. Yet, the emergence of resistant strains of the parasite would potentially limit the therapeutic efficacy of the drug [7].

With the increasing number of highrisk individuals, continuous efforts are necessary for generating novel treatment options against T.gondii infection [8]. Recent research studies have focused on developing 1 , $25(\mathrm{OH})_{2} \mathrm{D}_{3}$ as a potential therapeutic agent. In addition to its role in regulating calcium $(\mathrm{Ca})$ and 
phosphorus metabolism, vitamin $\mathrm{D}_{3}$ is an immune modulator $[\mathbf{9 , 1 0 ]}$. Kearns et al. [11] has demonstrated its therapeutic immunoregulatory effects in resolving various infectious diseases. The hormonal form of vitamin $\mathrm{D}, 1,25-$ dihydroxyvitamin $\mathrm{D}_{3}$, is known for its immunosuppressive, anti-proliferative and proapoptotic activities. An inhibitory effect of vitamin $\mathrm{D}_{3}$ on the immune system by targeting $\mathrm{T}$ helper 1(Th-1) lymphocytes has been described [12].

Nitazoxanide (NTZ) [2-acetyloxy-N-(5-nitro-2thiazolyl) benzamide] is a broad-spectrum antiparasitic compound. It acts against a wide range of cestodes, nematodes and protozoa with notable effects on apicomplexan parasites, particularly, Cryptosporidium parvum [13]. NTZ inhibits pyruvate-ferredoxin oxidoreductase (PFOR) enzyme which is necessary for anaerobic metabolism, without the formation of free radicals or deterioration of the host cells [14]. Nitazoxanide has been applied in different experimental models for the treatment of toxoplasmosis. Galvan-Ramirez et al. [15] reported that nitazoxanide drug reduced T.gondii infection more efficiently than pyrimethamine in cultured rat astrocytes and without causing any toxicity to the host cells.

Various studies have analyzed the role of vitamin $\mathrm{D}$ in different intracellular protozoan infections like; Leishmania Mexicana and malaria [16, 17]. Yet, there's quite a lack of reports which investigated its role in T.gondii infection. Hence, the present work aimed to evaluate the therapeutic effects of vitamin $\mathrm{D}_{3}$ as a sole agent and after its combination with nitazoxanide in $T$. gondii infected mice.

\section{MATERIALS AND METHODS}

\section{The avirulent (ME49) T.gondii strain:}

Regular maintenance of the strain was achieved through oral administration of the Swiss albino mice with diluted brain suspension of previously infected mice containing approximately $(25$ cysts in $0.1 \mathrm{ml})$. The process was repeated every $45-60$ days [18].

\section{Mice grouping and experimental design:}

The study was conducted at the post-graduate research laboratory at the Medical Parasitology Department, Faculty of Medicine, Zagazig University. It was carried out on 100 laboratory- bred Swiss albino male mice, aged 7 - 8 weeks, weighing 20-25 g. All mice were housed in wellventilated cages and were regularly offered standard pellet food and water [19]. Examination of mice faeces was performed to exclude any parasitic infections [20]. The selected mice were equally divided into the following groups:

(GI): Infected untreated control group.

(GII): Infected and treated by spiramycin.

(GIII): Infected and treated by vitamin $\mathrm{D}_{3}$.

(GIV): Infected and treated by nitazoxanide.

(GV): Infected and received a combination of vitamin $\mathrm{D}_{3}$ and nitazoxanide.

\section{Drugs:}

Spiramycin (Rovac $®$, Delta Pharma, Egypt) was administered at a dose of $400 \mathrm{mg} / \mathrm{kg} /$ day [21]. The drug was given at a fixed hour daily for seven days.

Nitazoxanide (Al- Andalous for pharmaceutical industries, Egypt) was given orally at a dose of $150 \mathrm{mg} / \mathrm{kg} / \mathrm{day}$, for 14 days, based on previous studies on experimental cryptosporidiosis [22].

Both spiramycin and nitazoxanide were administered starting from the 45th day postinfection, at the onset of chronic toxoplasmosis, according to the drug table of Paget and Barnes [23].

Vitamin $\mathrm{D}_{3}$ solution (Product No: 740292, Sigma-Aldrich, Cairo, Egypt) was administered intraperitoneally to each mouse at a dose of $0.5 \mu \mathrm{g} / \mathrm{kg} / 2$ days. The treatment began three days before the infection (two doses) and continued for 14 days (seven doses). The timing of commencing Vitamin $\mathrm{D}_{3}$ treatment as well as the duration of therapy were conducted according to the protocols described by Rajapakse et al. $[24,43]$.

Upon completion of the treatment, all animals were sacrificed after the last dose of therapy by cervical dislocation.

\section{Experimental infection:}

Infection of mice was initiated by oral administration of 25 cysts in $0.1 \mathrm{ml}$ of diluted brain suspension using a stomach tube. The infection was obtained from the brain tissues of another mouse, which was infected 45-60 days earlier [18]. The mouse was sacrificed and the brain was removed and homogenized in 1-ml saline under sterile conditions. A glass 
homogenizer was used to release tissue cysts. One drop $(25 \mu \mathrm{l})$ of the brain homogenate was spread on a slide and microscopically examined. Tissue cysts were then counted in four drops and multiplied by 10 to estimate the number of cysts in one $\mathrm{ml}$ of the brain suspension [25]. The infective dose was determined to be 25 cysts in $0.1 \mathrm{ml}$ of the brain suspension. Tissue cysts in brain homogenate of $T$. gondii infected mice are shown in Figure (1). The therapeutic effects of the used drugs were assessed using; parasitological, histopathological and immunological measures:

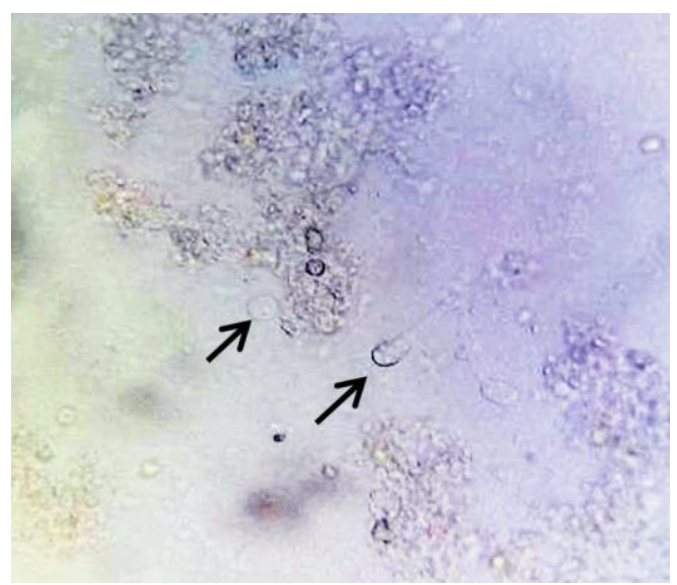

Figure 1: Toxoplasma gondii tissue cysts in brain suspension. Light microscopic examination of tissue cysts obtained in brain suspension of T.gondii infected mice (black arrows, X400)

\section{1- Parasitological assessment:}

\section{Parasite load:}

T.gondii tissue cysts containing bradyzoites were counted in Giemsa stained smears from the brain sections of all study groups. In each mouse, the brain tissues were examined using oil immersion. The mean value of 10 different fields was calculated for each group [26].

\section{Parasite reduction percentage $(\% \mathrm{R})$ :}

The reduction in the parasite burden was calculated using the following equation:

$$
\% \mathrm{R}=\frac{100(\mathrm{C}-\mathrm{E})}{\mathrm{C}}
$$

$\% \mathrm{R}: \%$ reductions, C: control group and $\mathrm{E}$ : experimental groups of mice [27].

\section{2- Histopathological assessment:}

Tissue samples from brain tissues were fixed in $10 \%$ formal saline solution, dehydrated in ascending grades of ethyl alcohol, then, they were cleared in xylol, and kept as paraffin blocks. Sections of $4 \mu \mathrm{m}$ thickness were cut and stained with haematoxylin and eosin (H\&E) [28]. All slides were then examined microscopically for detection of T.gondii tissue cysts. In the brain tissues, the total numbers of focal or diffuse inflammatory foci were counted and inflammatory infiltrations in the meninges were analyzed. The inflammatory score was represented as arbitrary units as follow; 0-2, mild; 2-4, moderate; 4-6, severe; and above 6, very severe [29].

\section{Immunological assessment:}

\section{Estimation of interferon-gamma (IFN- $\gamma$ ) levels by ELISA:}

Serum samples were obtained from all infected and control groups at the end of the study (60 days post-infection) [30]. Interferon-gamma (IFN- $\gamma$ ) levels in serum samples were estimated using Mouse IFN- $\gamma$ ELISA Set (BD Biosciences Pharmingen, Cat. No. 555138, San Diego, CA 92121, USA). The kit was used according to the manufacturer instructions. A photometric measurement at $450 \mathrm{~nm}$ was carried out to estimate the absorbance concentration of the samples.

\section{Statistical methods:}

Data were analyzed using Statistical Package for the Social Sciences "SPSS version 22". ANOVA F-test was performed to calculate the difference between quantitative variables among different study groups [31]. Quantitative data were described using mean and standard deviation (SD). $\mathrm{P}$ value $<0.05$ indicated significant results [32].

\section{RESULTS:}

\section{Parasitological results}

\section{Parasitic count}

Toxoplasma gondii tissue cysts were detected in impression smears from the brain tissues of all infected groups with variable densities. The mean values of the parasitic burden obtained in different study groups are demonstrated in Figure (2). Our results revealed a statistically significant difference in the mean cyst counts among the studied groups $(\mathrm{P}<0.001$, Table 1$)$. In the infected untreated group (GI), the mean count of tissue cysts per oil impression fields was (11.03 \pm 3.5$)$ (Table 1, Figure 2). In (GV), after 
combining vitamin $\mathrm{D}_{3}$ and nitazoxanide, the reduction percentage reached $(78.24 \%)$ with a highly significant difference as compared to the infected untreated group (GI) $(\mathrm{P}<0.001$, Table 1$)$. It was noted that, vitamin $\mathrm{D}_{3}$, used alone in (GIII), did not significantly reduce the parasitic load. The reduction percentage in cyst counts was only $(27.47 \%)$ (Table 1 ).

\section{2- Histopathological results:}

The brain sections of the infected untreated group (GI) showed multiple $T$. gondii cysts (Figure 3a), along with several pathological sequelae, like severe meningitis with marked mononuclear cellular infiltrations (Figure $3 \mathrm{~b}, \mathrm{c}$, respectively). Resolution of the pathological changes was reported in all of the treated groups. In (GIII), after administration of vitamin $\mathrm{D}_{3}$, a remarkable reduction in the degree of cellular inflammation was denoted (Figure 3d). Nitazoxanide induced a notable improvement in the degree of meningitis (Figure 3e). Degeneration of tissue cysts was demonstrated in (GV) (Figure 3f).
Forty (40\%) of T.gondii infected untreated mice (GI) exhibited severe inflammatory cellular infiltration. However, the severity percentage didn't exceed $(15 \%)$ among different treated groups (Figure 4). There was no significant difference in the degree of inflammatory infiltration changes among the treated groups $(\mathrm{P}$ $>0.05$, Table 2).

\section{3- Immunological results:}

\section{(IFN- $\gamma$ ) measurement:}

Serum levels of IFN- $\gamma$ were assessed as an indicator of the immunomodulatory effect of the different drugs used during the study (Figure 5). The infected untreated group (GI) showed a serum IFN- $\gamma$ level with a mean value of (125.2 \pm 39.9) $\mathrm{pg} / \mathrm{ml}$. The nitazoxanide-treated group (GIV) exhibited the highest level of IFN- $\gamma$ production $(280.7 \pm 88.8)$ with statistically significant difference, compared to (GI) (P < 0.001 , Table 3). On the other hand, the lowest serum levels of the cytokine $(93.23 \pm 25.6, \mathrm{P}<$ $0.05)$, were obtained in the vitamin $\mathrm{D}_{3}$-treated group (GIII), as shown in Table (3).

Table (1): The parasite count and reduction percentage in the brain tissues of different study groups .

\begin{tabular}{|l|c|c|c|c|c|c|c|}
\hline Brain /\% R & $\begin{array}{c}\text { GI } \\
(\mathbf{n = 2 0})\end{array}$ & $\begin{array}{c}\text { GII } \\
(\mathbf{n = 2 0})\end{array}$ & $\begin{array}{c}\text { GIII } \\
(\mathbf{n = 2 0})\end{array}$ & $\begin{array}{c}\text { GIV } \\
(\mathbf{n = 2 0})\end{array}$ & $\begin{array}{c}\text { GV } \\
(\mathbf{n = 2 0})\end{array}$ & F & P value \\
\hline Mean \pm SD & $11.03 \pm 3.5$ & $4.0 \pm 1.2^{\$}$ & $8.0 \pm 2.3$ & $5.6 \pm 1.8^{\$}$ & $2.4 \pm 0.8^{\$ \$}$ & 50.53 & $<\mathbf{0 . 0 0 1} * *$ \\
\% R & & $63.74 \%$ & $27.47 \%$ & $49.23 \%$ & $78.24 \%$ & & \\
\hline
\end{tabular}

GI: Infected untreated control group; GII: Infected-spiramycin treated group; GIII: Infected-vitamin $\mathrm{D}_{3}$ treated group; GIV: Infected-nitazoxanide treated group; GV: Infected and received combination of nitazoxanide and vitamin $\mathrm{D}_{3}$; \% R: percentage of reduction; SD: standard deviation; n: number of mice in each group.

F: $\mathrm{F}$ test (ANOVA); **P<0.001(statistically highly significant)

\$: significant with GI; \$ : highly significant with GI

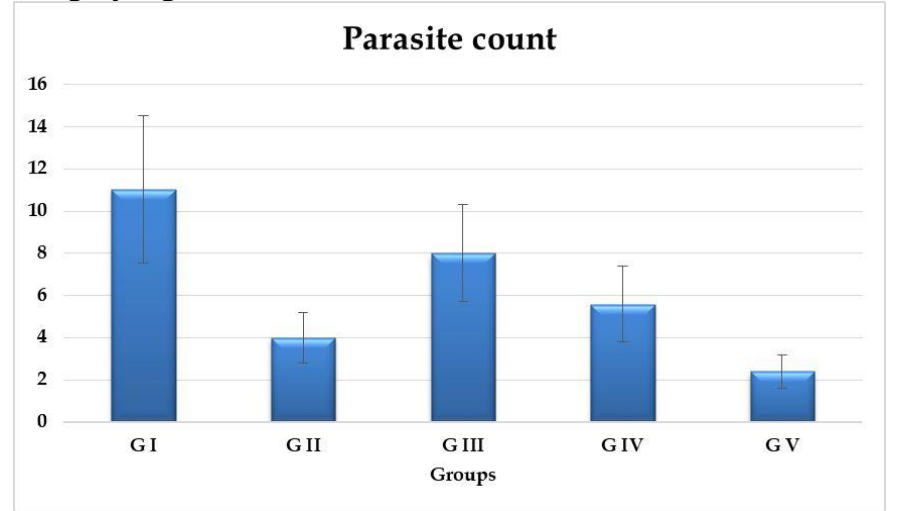

Figure 2: Parasite count in the brain sections of different groups. Mean T.gondii cysts count in the brain sections of different groups; GI: Infected untreated control group; GII: Infected-spiramycin treated group; GIII: Infected-vitamin $\mathrm{D}_{3}$ treated group; GIV: Infected-nitazoxanide treated group; GV: Infected and received combination of vitamin $\mathrm{D}_{3}$ and nitazoxanide. 

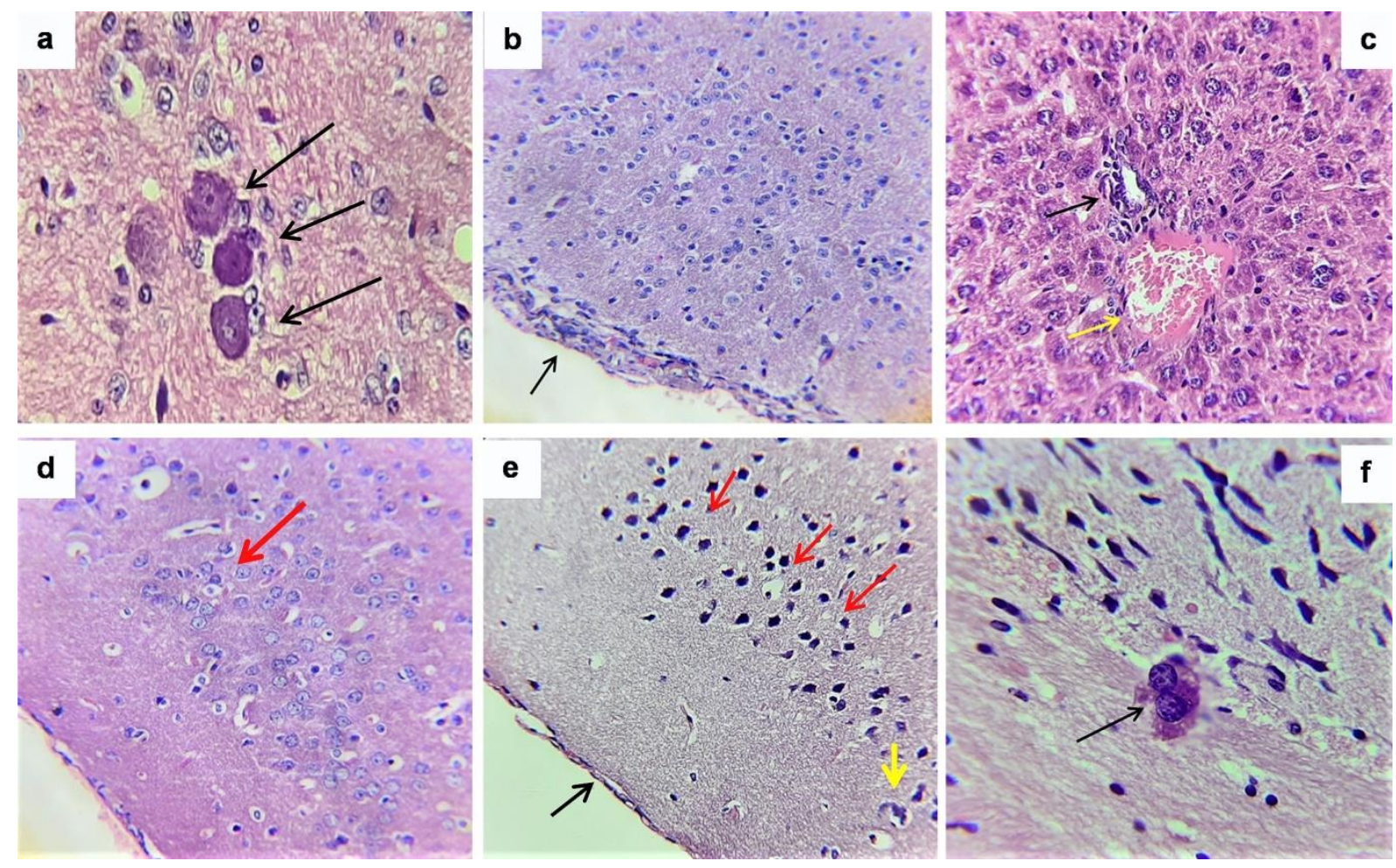

Figure 3: Histopathological findings in the brain sections of different infected mice. Brain sections of different groups: (a,b,c) Infected untreated control group (GI), showing (a) Multiple T. gondii cysts (black arrows) (b) Severe inflammation of the meninges (black arrow) (c) Severe mononucelar cellular infilartion (black arrow) and dilated vessel containing inflammatory cells (yellow arrow). (d) Brain section in the infected-vitamin $\mathrm{D}_{3}$ treatd group (GIII) showing mild infiltration of mononuclear cells (red arrow). (e) Brain section of the infected-nitazoxanide treated group (GIV) showing moderate cellular infiltrations (red arrows), mild meningitis (black arrow), with vascular congestion (yellow arrow) (f) Sections in the brain of the mice infected and received (vitamin $\mathrm{D}_{3}$ - nitazoxanide) combination $(\mathrm{GV})$, showing degeneration of existing $T$. gondii cyst (black arrow) [H\&E stain, X 400].

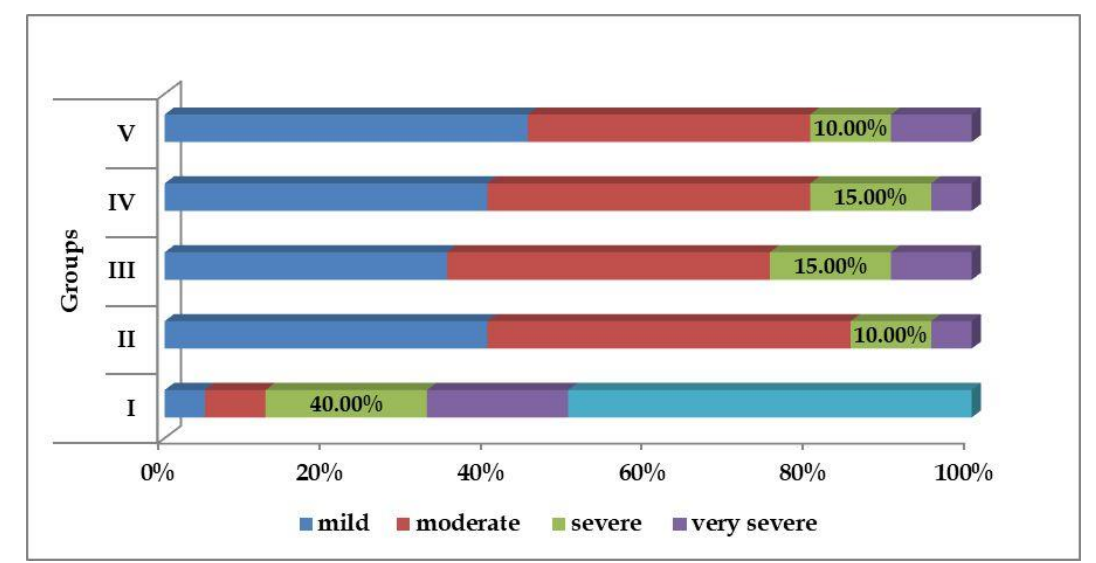

Figure 4: Inflammatory infiltration changes in the brain sections of different study groups. Distribution of cellular inflammatory infiltrations among different groups: GI: Infected untreated control group; GII: Infected-spiramycin treated group; GIII: Infected-vitamin $\mathrm{D}_{3}$ treated group; GIV: Infected-nitazoxanide treated group; $\mathrm{GV}$ : Infected and received (vitamin $\mathrm{D}_{3}$-nitazoxanide) combination. 
Table (2): Inflammatory infiltration changes among experimentally treated groups.

\begin{tabular}{|c|c|c|c|c|c|c|c|c|c|c|c|}
\hline \multirow{2}{*}{$\begin{array}{c}\text { Inflammatory } \\
\text { infiltration } \\
\text { degrees }\end{array}$} & \multicolumn{2}{|c|}{$\begin{array}{c}\text { GII } \\
(\mathbf{n}=20)\end{array}$} & \multicolumn{2}{|c|}{$\begin{array}{c}\text { GIII } \\
(\mathbf{n}=20)\end{array}$} & \multicolumn{2}{|c|}{$\begin{array}{c}\text { GIV } \\
(\mathbf{n}=20)\end{array}$} & \multicolumn{2}{|c|}{$\begin{array}{c}\mathbf{G V} \\
(\mathbf{n}=\mathbf{2 0})\end{array}$} & \multirow{2}{*}{$\chi^{2}$} & \multirow{2}{*}{ DF } & \multirow[b]{2}{*}{ P value } \\
\hline & $\mathbf{N}$ & $\%$ & $\mathbf{N}$ & $\%$ & $\mathbf{N}$ & $\%$ & $\mathbf{N}$ & $\%$ & & & \\
\hline Mild & 8 & $40.00 \%$ & 7 & $35.00 \%$ & 8 & $40.00 \%$ & 9 & $45.00 \%$ & \multirow{4}{*}{1.57} & \multirow{4}{*}{9} & \multirow{4}{*}{$\begin{array}{c}0.99 \\
\text { NS }\end{array}$} \\
\hline Moderate & 9 & $45.00 \%$ & 8 & $40.00 \%$ & 8 & $40.00 \%$ & 7 & $35.00 \%$ & & & \\
\hline Severe & 2 & $10.00 \%$ & 3 & $15.00 \%$ & 3 & $15.00 \%$ & 2 & $10.00 \%$ & & & \\
\hline Very severe & 1 & $5.00 \%$ & 2 & $10.00 \%$ & 1 & $5.00 \%$ & 2 & $10.00 \%$ & & & \\
\hline
\end{tabular}

GI: Infected untreated control group; GII: Infected-spiramycin treated group; GIII: Infected-vitamin $\mathrm{D}_{3}$ treated group; GIV: Infected-nitazoxanide treated group; GV: Infected and received combination of nitazoxanide and vitamin $\mathrm{D}_{3} ; \mathrm{n}$ : number of mice in each group.

$\chi 2$ : Chi square test; DF: Degree of freedom; NS: P>0.05 (statistically non-significant)

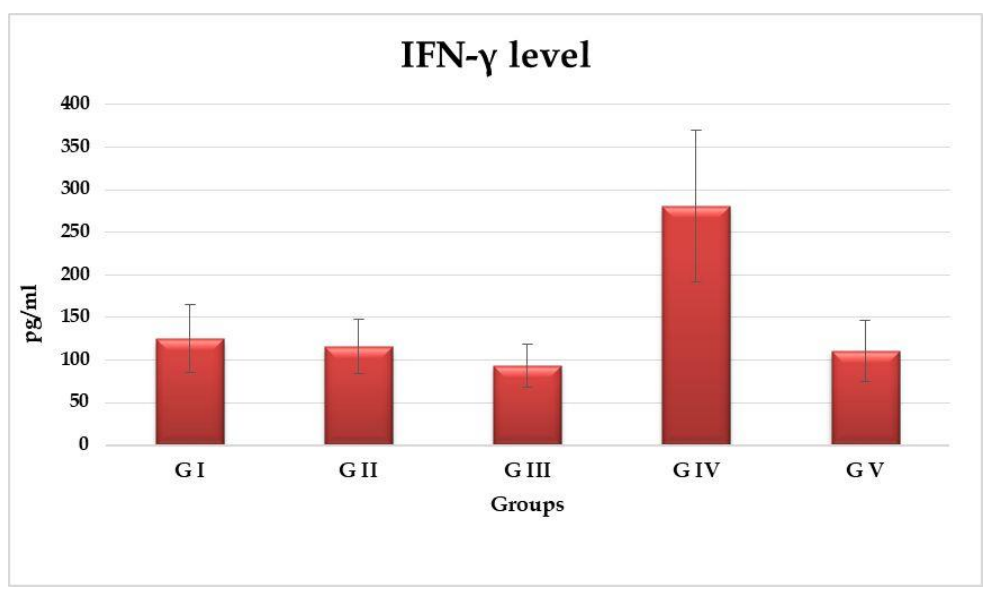

Figure 5: IFN- $\gamma$ serum Levels in different groups. Mean values of IFN- $\gamma$ serum Level $(\mathrm{pg} / \mathrm{ml})$ in different study groups: GI: Infected untreated control group; GII: Infected and treated by spiramycin; GIII: Infected and treated by vitamin $\mathrm{D}_{3}$; GIV: Infected and treated by nitazoxanide; GV: Infected and received (vitamin $\mathrm{D}_{3}$-nitazoxanide) combination.

Table (3): IFN- $\gamma$ Level (pg/ml) in serum samples of different study groups.

\begin{tabular}{|l|c|c|c|c|c|c|c|}
\hline IFN- $\boldsymbol{\gamma}$ & $\begin{array}{c}\text { GI } \\
(\mathbf{n}=\mathbf{2 0})\end{array}$ & $\begin{array}{c}\text { GII } \\
(\mathbf{n = 2 0})\end{array}$ & $\begin{array}{c}\text { GIII } \\
(\mathbf{n}=\mathbf{2 0})\end{array}$ & $\begin{array}{c}\text { GIV } \\
(\mathbf{n}=\mathbf{2 0})\end{array}$ & $\begin{array}{c}\text { GV } \\
(\mathbf{n}=\mathbf{2 0})\end{array}$ & F & P \\
\hline Mean \pm SD & $125.2 \pm 39.9$ & $115.6 \pm 32.2$ & $93.23 \pm 25.6^{\mathbf{1}}$ & $280.7 \pm 88.8^{\mathbf{\$}}$ & $110.45 \pm 36.3$ & 47.14 & $<\mathbf{0 . 0 0 1} * *$ \\
\hline
\end{tabular}

GI: Infected untreated control group; GII: Infected-spiramycin treated group; GIII: Infected-vitamin D3 treated group; GIV: Infected-nitazoxanide treated group; GV: Infected and received combination of nitazoxanide and vitamin $\mathrm{D}_{3}$; SD: standard deviation; IFN- $\gamma$ : Interferon-gamma; $n$ : number of mice in each group.

F: F test (ANOVA); **P $<0.001$ (statistically highly significant)

\$: significant with GI; \$ \$: highly significant with GI

\section{DISCUSSION}

Over the past 20 years, the treatment scheme of human toxoplasmosis remained unchanged [33]. Most of the currently used therapeutic drugs are associated with numerous and severe side effects [34]. Furthermore, owing to the growing resistance of the parasite, the current antiToxoplasma drugs have become less effective due to the evolving genetic mutations [35]. In line with this, the search for alternative drugs or drug combinations demands a challenging effort [4].
The antimicrobial effects of vitamin $\mathrm{D}_{3}$ are due to its over-expression of different antimicrobial peptides such as beta-defensin 2 and cathelicidin [36]. Moreover, vitamin $\mathrm{D}_{3}$ is a good inducer of nitric oxide (NO) production [37], which in turn, has potent antimicrobial and anti-parasitic properties [38].

Nitazoxanide (NTZ) was used in the treatment of different parasitic infections. It has shown excellent in vitro activities against a wide variety of protozoa and helminths [39]. Several recently conducted studies have managed to evaluate the 
effect of the drug in experimental T.gondii infection [34, 40, 41].

Our study has demonstrated a significant difference $(\mathrm{P}<0.001)$ in the mean T.gondii cysts count among different groups. A notable reduction in the parasitic load was demonstrated in (GII), after spiramycin intake (Table 1). The anti-parasitic potential of spiramycin against T.gondii was supported by Grujić et al. [42] who reported the ability of the drug to effectively reduce cyst numbers in both acute and chronic murine toxoplasmosis. The current study also denoted that despite the reduction in the parasitic load in the vitamin $\mathrm{D}_{3}$,-treated group (GIII), the difference was not statistically significant (P>0.05) when compared with (GI) (Table 1). Likewise, Rajapakse et al. [43] have proved the role of vitamin $\mathrm{D}_{3}$ in reducing the parasitic burden in T.gondii infected mice by inhibiting the intracellular proliferation of the parasite. Conversely, Ghaffarifar et al. [44] have reported that using vitamin $\mathrm{D}_{3}$ did not have any considerable effect on the inhibition of tachyzoites proliferation in mice experimentally infected with the virulent (RH) T.gondii strain.

According to our results, the combination between vitamin $\mathrm{D}_{3}$ and nitazoxanide in $(\mathrm{GV})$ has significantly reduced the parasitic count $(\mathrm{P}<0.001$, Table 1). Different combination trials have been experimentally introduced for the treatment of toxoplasmosis. Etewa et al. [45] presented a combination between spiramycin and methotrexate. Yet, they reported an increase in the cysts number in the brain tissues of the experimentally treated mice. Omar et al. [46] denoted that the combination between spiramycin and the anti-inflammatory drug, aminoguanidine, significantly reduced the parasitic burden in T.gondii infected mice.

Histopathological findings in the present work, have matched the parasitological results. The infected untreated group (GI) which exhibited the highest parasitic load (Table 1), had also shown several pathological alterations, like; severe meningeal inflammation and marked mononuclear cellular infiltrations (Figure $3 \mathrm{~b}, \mathrm{c}$, respectively). The study has also reported a notable reduction in the degree of cellular inflammatory infiltrations in the vitamin- $\mathrm{D}_{3}$ treated group (GIII) (Figure 3d). These results come in accordance with Rajapakse et al. [24] and Rajapakse et al. [43] who reported improvement of pathological changes along with a reduction in the parasite burden after vitamin $\mathrm{D}_{3}$ treatment in T.gondii infected mice.

A marked reduction in the degree of meningitis was noticed after administration of nitazoxanide in (GIV) (Figure 3e). The promising effect of nitazoxanide in reducing the degree of inflammation in brain tissues of $T$. gondii infected mice was endorsed by El-Kowrany et al. [40]. The combination between vitamin $\mathrm{D}_{3}$ and nitazoxanide in $(\mathrm{GV})$ has induced a noted reduction in the severity of pathological changes as well as degeneration of existing tissue cysts (Figure 3f).

In our study, we obtained the highest significant level of IFN- $\gamma$ production $(280.7 \pm 88.8, \mathrm{P}<0.001)$ in the nitazoxanide treated group (GIV) (Table 3 ). This finding could be attributed to the fact that nitazoxanide is a strong inducer of the Th1 immune response and in turn, IFN- $\gamma$ release, which controls tachyzoites replication, as confirmed by Munoz et al.[47]. In contrast, the lowest level of the cytokine was detected in the vitamin $\mathrm{D}_{3}$-treated group (GIII) with a mean value of $(93.23 \pm 25.6)$ (Table 3). Rajapakse et al. [24] explained that the relatively low serum IFN$\gamma$ level in vitamin $\mathrm{D}_{3}$ treated mice was due to its inhibitory effect on Th1 immune cells and consequently impairing IFN- $\gamma$ production. They also confirmed that despite the immunesuppressive effect of the vitamin, no increase in parasite load was observed, which indicated that vitamin $\mathrm{D}_{3}$ inhibits $\mathrm{T}$.gondii proliferation at a cellular level.

According to the obtained results, a balanced level of IFN- $\gamma$ was demonstrated in (GV) with a mean value of $(110.45 \pm 36.3)$. The detected IFN$\gamma$ measurement was not as low as the level obtained in the vitamin $\mathrm{D}_{3}$ treated group (93.23 \pm 25.6), neither as high as that exhibited in the nitazoxanide treated mice $(280.7 \pm 88.8, \mathrm{P}<0.001)$ (Table 3). Hence, our research verified that combining both nitazoxanide and vitamin $\mathrm{D}_{3}$ has created a delicate modulation in the overall immune response against toxoplasmosis.

\section{CONCLUSIONS:}

Results of the current research showed that using vitamin $\mathrm{D}_{3}$ alone did not significantly reduce the parasitic load in the brain sections of T.gondii infected mice. However, after its combination with nitazoxanide, a significant reduction was obtained. We have also shown that the drug 
combination has induced a notable balance in the immune response against toxoplasmosis. Therefore, we recommend using vitamin $\mathrm{D}_{3^{-}}$ nitazoxanide drug combination as a promising alternative treatment option for T.gondii infection.

Funding: This research did not receive any specific grant from funding agencies in the public, commercial, or not-for-profit sectors.

Conflicts of interest: The authors report no conflicts of interest regarding the publication of this manuscript.

\section{Ethical considerations}

The current research was approved by the Ethical Committee of Zagazig University and was conducted according to the international regulations and guidelines of animal experiments.

\section{HIGHLIGHTS:}

- Till now, there is no available single gold standard treatment for toxoplasmosis.

- Vitamin $\mathrm{D}_{3}$ has potent antimicrobial and antiparasitic properties.

- Using vitamin D3 alone in the treatment of toxoplasmosis had no significant impact on the parasitic burden.

- Vitamin $\mathrm{D}_{3}$-nitazoxanide drug combination induced a significant balance in the immune response against toxoplasmosis.

- Vitamin $\mathrm{D}_{3}$-nitazoxanide drug combination would be a promising alternative treatment option for Toxoplasma gondii infection..

\section{REFERENCES}

1. Flegr J, Prandota J, Sovickova M, Israili ZH. Toxoplasmosis-a global threat. Correlation of latent toxoplasmosis with specific disease burden in a set of 88 countries. PLOS ONE 2014; 9(3): e90203.

2. Halonen SK, Weiss LM. Toxoplasmosis. Handb Clin Neurol 2013; 114, 125-145.

3. Yarovinsky F. Innate immunity to Toxoplasma gondii infection. Nat Rev Immunol 2014; 1 4, 109-121.

4. Shammaa AM, Powell TG, Benmerzouga I. Adverse outcomes associated with the treatment of Toxoplasma infections. Scientific reports 2021; 11(1):1-8.
5. Araujo FG, Shepard RM, Remington JS. In vivo activity of the macrolide antibiotics azithromycin, roxithromycin and spiramycin against Toxoplasma gondii. Eur J Clin Microbiol Infect Dis 1991; 10(6): 519-524.

6. Perng C, Kearney A, Palepu N, Smith B, Azzarano L. Assessment of oral bioavailability enhancing approaches for SB-247083 using flowthrough cell dissolution testing as one of the screens. Int J Pharm 2003; 250:147-156.

7. -Vaz R, Thomaz S, Sumikawa E, Guimaraes A. Serological prevalence of Toxoplasma gondii antibodies in pregnant women from Southern Brazil. Parasitol Res 2011; 106:661-5.

8. Montazeri M, Sharif M, Sarvi S, Mehrzadi S, Ahmadpour E, Daryani A. A Systematic Review of In vitro and In vivo Activities of AntiToxoplasma Drugs and Compounds (2006-2016). Front Microbiol 2017; 8:25.

9. -Huhtakangas JA, Veijola J, Turunen S, Karjalainen A, Valkealahti M, Nousiainen T, YliLuukko S, Vuolteenaho O, Lehenkari P. $1,25(\mathrm{OH}) 2 \mathrm{D} 3$ and calcipotriol, its hypocalcemic analog, exert a long-lasting anti-inflammatory and anti-proliferative effect in synoviocytes cultured from patients with rheumatoid arthritis and osteoarthritis. J Steroid Biochem Mol Biol 2017; 173:13-22.

10. Murdaca G, Gerosa A, Paladin F, Petrocchi L, Banchero S, Gangemi S. Vitamin D and Microbiota: Is There a Link with Allergies? Int $J$ Mol Sci. 2021; 22(8):4288.

11. Kearns MD, Alvarez JA, Seidel N, Tangpricha V. Impact of Vitamin D on Infectious Disease. Am J Med Sci 2015; 349(3): 245-262.

12. Redaelli CA, Wagner M, Tien YH, Mazzucchelli L, Stahel PF, Schilling MK et al. $1 \alpha, 25$ Dihydroxycholecalciferol reduces rejection and improves survival in rat liver allografts. Hepatology 2001; 34(5):926-34.

13. Esposito M, Stettler R, Moores SL, Pidathala C, Müller N, Stachulski A et al. In vitro efficacies of nitazoxanide and other thiazolides against Neospora caninum tachyzoites reveal antiparasitic activity independent of the nitro group. Antimicrob Agents Chemother 2005; 49(9): 37153723.

14. Dupouy-Camet J. New drugs for the treatment of human parasitic protozoa. Parassitologia 2004; 46(1-2):81-84.

15. Galvan-Ramirez Mde L, Duenas Jimenez JM, Rocio L, Troyo-Sanroman R, Ramirez-Herrera M, Garcia-Iglesias T. Effect of nitaxozanide and pyrimethamine on astrocytes infected by 
Toxoplasma gondii in vitro. Arch Med Res 2013; 44 (6): 415-421.

16. Ramos-Martínez E，Villaseñor-Cardoso MI, López-Vancell MR, García-Vázquez FJ, PérezTorres A. Effect of $1,25(\mathrm{OH}) 2 \mathrm{D} 3$ on $\mathrm{BALB} / \mathrm{c}$ mice infected with Leishmania mexicana. Exp Parasitol 2013; 134 (4):413-21.

17. Bivona G, Agnello L, Lo Sasso B, Scazzone C, Butera D, Gambino CM, et al. Vitamin D in malaria: more hypotheses than clues. Heliyon 2019; 5(2):e01183.

18. Fuentes-Castro BE, Reyes-García JG, ValenzuelaVargas MT, Martínez-Gómez F. Histopathology of murine toxoplasmosis under treatment with dialyzable leukocyte extract. Mem Inst Oswaldo Cruz 2017; 112 (11): 741-747.

19. El-Fakhry Y, Achbarou A, Desportes I, Mazier D. Encephalitozoon intestinalis: humoral responses in interferon-c receptor knockout mice infected with a microsporidium pathogenic in AIDS patients. Exp Parasitol 1998; 89:113-121.

20. Garcia LS, Bruckner DA. Macroscopic and microscopic examination of fecal specimens. In: Giboda MN, Vokurkova P, Kopacek O. Diagnostic medical parasitology, 3rd ed. ASM Press, Washington 1977; 608-649.

21. Chew WK, Segarra I, Ambu S, Mak JW. Significant reduction of brain cysts caused by Toxoplasma gondii after treatment with spiramycin co-administered with metronidazole in a mouse model of chronic toxoplasmosis. Antimicrob Agents Chemother 2012;56(4):17621768.

22. Rossignol JF, Ayoub A, Ayers MS. Treatment of diarrhea caused by Cryptosporidium parvum: a prospective randomized, double-blind, placebo controlled study of Nitazoxanide. J Infect Dis 2001;184 (1): 103-106.

23. Paget GE, Barnes JM. Evaluation of results: Qualitative application in different species. In: Laurence DR, Backarach AL (eds.), Evaluation of drug activities. Pharmacometrics. Academic press, London and New York 1964; 1; 160-167.

24. Rajapakse R, Mousli M, Pfaff AW, UringLambert B, Marcellin L, Bronner C. 125dihydroxyvitamin D3 induces splenocyte apoptosis and enhances BALB/c mice sensitivity to toxoplasmosis. J Steroid Biochem Mol Biol 2005;96: 179-185.

25. Djurković-Djaković O, Milenković V, Nikolić A, Bobić B, Grujić J. Efficacy of atovaquone combined with clindamycin against murine infection with a cystogenic (Me49) strain of Toxoplasma gondii. J Antimicrob Chemother 2002; 50 (6): 981-987.
26. Barakat AMA. Some diagnostic studies on male New Zealand rabbit experimentally infected with Toxoplasma gondii strain. Glob Vet 2007; 1:1723.

27. Penido MLO, Nelson DL, Vieira LQ, Coelho PMZ. Schistosomal activity of alkyl aminooctanethiosulfuric acids. Mem Inst Oswaldo Cruz 1994; 89(4):595-602.

28. Drury RAB, Wallington EA. Carleton's histological technique, 5th edn. Oxford University Press, Oxford, New York, Toronto 1980.

29. Silva NM, Vieira JC, Carneiro CM, Tafuri WL. Toxoplasma gondii: the role of IFN-gamma, TNFRp55 and iNOS in inflammatory changes during infection. Exp Parasitol 2009; 123(1):6572.

30. Nance JP, Vannella KM, Worth D, David C, Carter D, Noor, S. Chitinase dependent control of protozoan cyst burden in the brain. PLoS Pathog 2012; 8 (11): e1002990.

31. Chan YH. Biostatistics 102: quantitative dataparametric \& non-parametric tests. Singap Med J 2003; 44(8):391-396.

32. Leslie E, Geoffrey J, James M. Statistical analysis. In: Kirkpatrick LA, Feeney BC (eds) Interpretation and uses of medical statistics, 4th edn. Oxford Scientific Publications, Oxford 1991; 411- 416.

33. Konstantinovic N, Guegan H, Stäjner T, Belaz S, Robert-Gangneux F. Treatment of toxoplasmosis: Current options and future perspectives. Food Waterborne Parasitol 2019; 1:15, e00036.

34. Farahat Allam A, Shehab AY, Fawzy Hussein Mogahed NM, Farag HF, Elsayed Y, Abd El-Latif NF. Effect of nitazoxanide and spiramycin metronidazole combination in acute experimental toxoplasmosis. J Parasit Dis 2020;6(4):e03661.

35. Montazeri M, Mehrzadi S, Sharif M, Sarvi S, Tanzifi A, Aghayan SA. Drug resistance in Toxoplasma gondii. Front Microbiol 2018; 9: 2587.

36. Routsias JG, Karagounis P, Parvulesku G, Legakis NJ, Tsakris A. In vitro bactericidal activity of human beta defensin 2 against nosocomial strains. Peptides 2010; 31:1654 1660 .

37. Morris A, Seivaraj RK. In vitro 25hydroxycholecalciferol treatment of lipopolysaccharide-stimulated chicken macrophages increases nitric oxide production and mRNA of interleukin-1 beta and 10. Vet Immunol Immunopathol 2014; 161: 265-270.

38. Nouari W, Ysmail-Dahlouk L, Aribi M. Vitamin D3 enhances bactericidal activity of macrophage 
against Pseudomonas aeruginosa. Int Immunopharmacol 2016; 30: 94-101.

39. Fox LM, Saravolatz LD. Nitazoxanide: a new thiazolide antiparasitic agent. Clin Infect Dis 2005;40 (8):1173-1180.

40. El-Kowrany SI, Abd El Ghaffar AES, Shoheib ZS, Mady RF, Gamea GAM. Evaluation of nitazoxanide as a novel drug for the treatment of acute and chronic toxoplasmosis. Acta tropica 2019; 195:145-154.

41. Saleh M, Nagaty I, Zalat R, Yaseen D, Ahmed K, Abdelhameed R. Assessment of Nitazoxanide Loaded on Silver nanoparticles Efficacy on Treatment of Murine Model of Chronic Toxoplasmosis. Benha Medical Journal 2021; 38: 186-199.

42. Grujić J, Djurković-Djaković O, Nikolić A, Klun I, Bobić B. Effectiveness of spiramycin in murine models of acute and chronic toxoplasmosis. Int $J$ Antimicrob Agents 2005; 25(3):226-30.

43. Rajapakse R, Uring-Lambert B, Andarawewa KL, Rajapakse RP, Abou-Bacar A, Marcellin L, et al. $1,25(\mathrm{OH}) 2 \mathrm{D} 3$ inhibits in vitro and in vivo intracellular growth of apicomplexan parasite
Toxoplasma gondii. J Steroid Biochem Mol Biol 2007;103:811-814.

44. Ghaffarifar F, Abdolah Pour M, Sharifi Z, Dalimi Asl A, Al-Kawaz E. The Effect of Vitamin $\mathrm{D}_{3}$ Alone and Mixed With IFN- $\gamma$ on Tachyzoites of Toxoplasma gondii (RH Strain) Proliferation and Nitric Oxide (NO) Production in Infected Macrophages of BALB/C Mice. Iran J Parasitol 2010;5(3):48-56.

45. Etewa SE, Abo El-Maaty DA, El-Azeem A, Mai E, El-Shafey MA, Sarhan MH. In Vivo Assessment of the Effects of Methotrexate on Latent Toxoplasmosis. J Egypt Soc Parasitol 2017;47(3): 589 - 598.

46. Omar M, Abaza BE, Mousa E, Ibrahim SM, Rashed HE, Farag TI. Effect of spiramycin versus aminoguanidine and their combined use in experimental toxoplasmosis. J Parasit Dis 2021; $45,1014-1025$.

47. Munoz M, Liesenfeld O, Heimesaat MM. Immunology of Toxoplasma gondii. Immunol Rev 2011;240 (1): 269-285. 